\title{
MECHANISMS OF DOPING METALS FROM GAS AND LIQUID MEDIUMS BY THE $\mathrm{mS-LONG}$ Nd-LASER PULSES
}

V.M. BORISOV, A.M. KOVALEVICH and Yu.Yu. STEPANOV

The Troitsk Kurchatov Research Institute, Troitsk, Moscow Region 142092, USSR

Ultra-high concentrations (67 atom1c per cent) doping elements (carbon) have been reached in the suggested method of the laser treatment of the metals under liquid. The system 1ron-toluol was used in this experiment as an example. The mechanism of trasportation of doping elements into the melt zone (thickness up $100 \mu \mathrm{m})$ is shown to be determined both experimentally and numerically by convectional miring of the melt metal because of the action of backing rapor forces.

The treatment of the metals $\left(I=1 \div 5 \times 10^{5} \mathrm{~W} / \mathrm{cm}^{2}\right)$ in the gas -reagents with varlous chemlcal activety has demonstrated that the dop1ng process has a character of thermo-chemical interaction of the melt metals with ambient gas. The following table represents some microhardneses and nitrogen concentrations for $\mathrm{Fe}$ and $\mathrm{Tl}$ samples treated in $\mathrm{N}_{2}$ and $\mathrm{NH}_{3}$ gases at near 1 atm.:

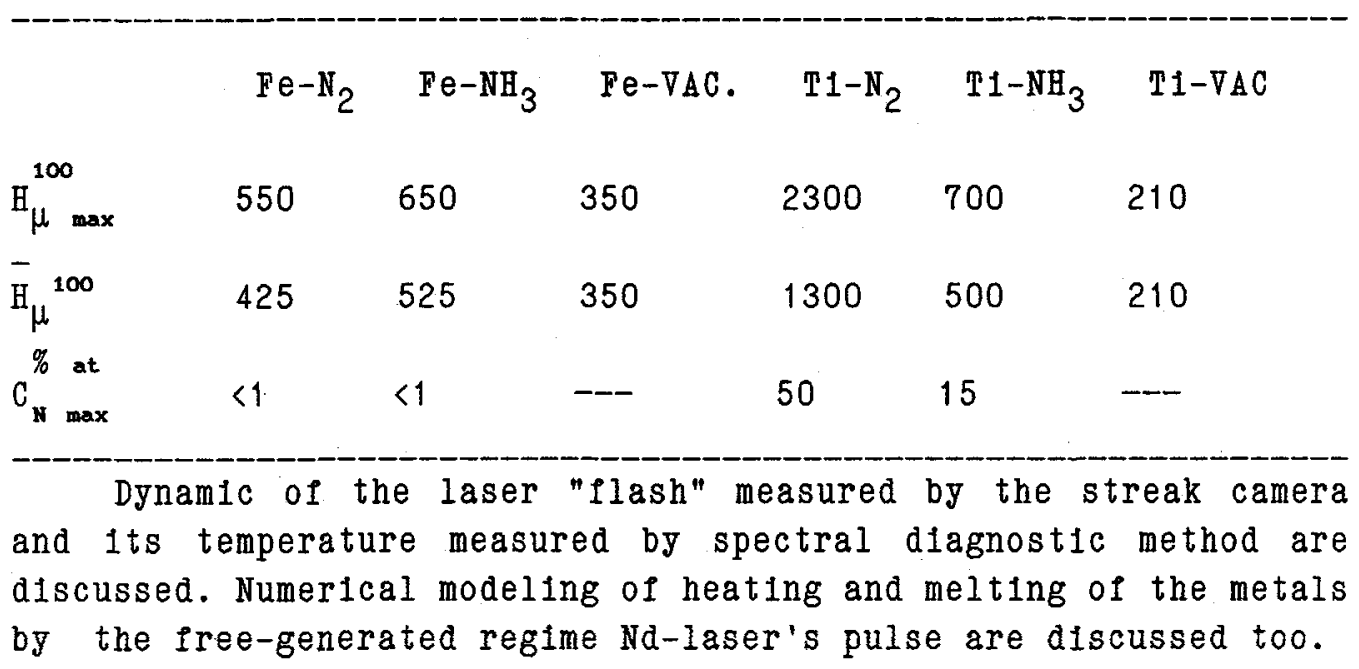

